\title{
TIENEN DERECHO A LA INTIMIDAD EL NIÑO DE LA PLAYA Y SU \\ FAMILIA ${ }^{1}$
}

\author{
Ramón Herrera de las Heras
}

Alba Paños Pérez

Investigadores del Proyecto "La protección de los menores en el ámbito audiovisual"

En el día de ayer medios de comunicación de todo el mundo publicaron una imagen estremecedora donde se ve un niño sirio muerto en una playa turca. La fotografía ha impactado tanto a nuestra sociedad que ha conseguido, si quiera por un momento, atraer la atención sobre el problema de los refugiados y avivar el debate de la necesaria cooperación de Europa en éste ámbito.

Muchos periódicos debatieron sobre la conveniencia o no de publicar la dura imagen en sus portadas. Unos, como el diario $A B C$, optaron por no hacerlo, otros, como El Mundo, lo hicieron con la cara del menor pixelada, y otros, como El Diario de Almería, lo hicieron con la fotografía sin modificación alguna. Desde el punto de vista ético estoy convencido que no es un debate sencillo; tampoco lo es en el ámbito del Derecho, pues conlleva múltiples interrogantes. ¿Tiene derecho a la intimidad el fallecido? ¿Podría la familia pedir que no se publicase la foto? ¿Ha de impedirse la identificación del menor? ¿Prima el derecho a la información y la necesidad de remover conciencias? Trataré, de forma breve, de dar claridad sobre estos asuntos.

Aunque para los no avezados pueda parecer una contradicción, en este caso no nos encontramos ante la protección del derecho a la imagen del menor, sino que nos referimos al derecho a su intimidad -intimidad familiar, como veremos más adelante.Decía el gran jurista CASTÁN que éste derecho de la personalidad “concede un poder a las personas para proteger la esencia de su personalidad y sus más importantes cualidades." El artículo 20.4 de la Constitución Española establece que las libertades de información y expresión "tienen su límite en el respeto a los derechos reconocidos en

\footnotetext{
${ }^{1}$ Este trabajo ha sido publicado también en El Diario de Almería
} 
este Título, en los preceptos de las leyes que lo desarrollen y, especialmente, en el derecho al honor, a la intimidad, a la propia imagen y a la protección de la juventud y de la infancia". Esta confrontación del derecho a la libertad informativa y la protección de la juventud y la infancia está claramente regulada, además, en el artículo 39.2 CE, donde se ordena a los poderes públicos otorgar la máxima protección al menor y en el artículo 25 de la Declaración Universal de los Derechos Humanos, que protege la infancia y la maternidad.

Tanto la jurisprudencia como la doctrina son claramente favorables a la libertad de información en caso de confrontación de estos derechos en personas mayores de edad, si bien ofrecen una mayor preeminencia al derecho a la intimidad de los menores de edad, en orden a proteger ese interés superior de los mismos. De ahí que el tratamiento de las informaciones relativas a los menores deba realizarse bajo un prisma de mayor garantía de los derechos fundamentales y de interpretación restrictiva del ejercicio de la libertad de información y expresión.

Sin embargo, no debemos olvidar que es necesario buscar un equilibrio entre esta protección a los menores y el derecho a recibir información que tienen todos los ciudadanos por aplicación estricta del derecho a las libertades de expresión e información así como a la libertad de prensa. Y más aún en un tema de evidente interés general y alarma social.

Pues bien, del análisis jurisprudencial se desprende que los criterios de ponderación genéricos para determinar cuándo la intromisión la intimidad es legítima, es decir, cuándo la libertad de información prima sobre este derecho, son los siguientes: que lo difundido tenga interés público, que sea veraz y que no sea gratuito, es decir, que la información contribuya a formar la opinión pública. Parece claro, en mi opinión que todos estos requisitos se cumplen en el caso del menor sirio. Pero estos criterios genéricos deben ser ampliados y matizados respecto de los menores de edad. De forma que, en su caso, no serán suficientes para su protección, debiendo atender siempre en primer lugar al principio de no identificación del menor. Y ello porque los datos que permiten la identificación del menor no contribuyen al interés público de la información ni tampoco aportan nada a la formación de la opinión pública. O, dicho de otro modo, se podrá sacrificar la intimidad de un menor a favor de la libertad de información solamente cuando concurran los siguientes requisitos mínimos: que la 
información que se difunda sea veraz, que tenga un interés público relevante y que no lesione el interés del menor.

Pero es que en este caso nos encontramos con que el menor ha fallecido y, tratándose el derecho a la intimidad de un derecho de la personalidad, éste se extingue con su muerte. Aunque no debemos de olvidar que nuestro Tribunal Constitucional ha establecido que, incluso cuando haya fallecido el titular del derecho a la intimidad, se mantiene la existencia del derecho a la intimidad familiar, cuyos titulares son los parientes más próximos porque "su repercusión moral, es también un derecho de sus familiares."

En conclusión, los medios solamente deberían abstenerse de publicar la foto si el padre del niño fallecido se negase a que la foto fuese difundida. Vistas las declaraciones recientes del padre en las que señala que "quiero que el mundo entero nos escuche desde Turquía, donde hemos llegado escapando de la guerra... Hago esta declaración para evitar que otras personas tengan el mismo sufrimiento", no existe impedimento legal alguno en que la fotografía se publique sin ser pixelada. 